This document is the Accepted Manuscript version of a Published Work that appeared in final form in Analytical Chemistry, copyright (c) American Chemical Society after peer review and technical editing by the publisher. To access the final edited and published work see:

https://dx.doi.org/10.1021/acs. analchem.9b02560. 


\title{
Experimental Comparison in Sensing Breast Cancer Mutations by Signal ON and Signal OFF Paper-Based Electroanalytical Strips
}

\author{
Stefano Cinti, ${ }^{*}$ Giulia Cinotti, ${ }^{\dagger}$ Claudio Parolo, ${ }^{\alpha}$ Emily P. Nguyen, ${ }^{\alpha}$ Veronica Caratelli, ${ }^{\dagger}$ Danila Mo- \\ scone, ${ }^{\dagger}$ Fabiana Arduini ${ }^{\dagger}$, and Arben Merkoci ${ }^{*} \alpha, 1$ \\ ${ }^{\S}$ Department of Pharmacy, University of Naples “Federico II”, Via D. Montesano 49, 80131 Naples, Italy. \\ ${ }^{\alpha}$ Nanobioelectronics \& Biosensors Group, Catalan Institute of Nanoscience and Nanotechnology (ICN2), CSIC and BIST, \\ Campus UAB, Bellaterra, 08193 Barcelona, Spain. \\ ${ }^{\dagger}$ Department of Chemical Science and Technologies, University of Rome "Tor Vergata”, Via della Ricerca Scientifica 1, \\ 00133 Rome, Italy. \\ ' ICREA, Institució Catalana de Recerca i Estudis Avançats, Pg. Lluís Companys 23, 08010 Barcelona, Spain. \\ *Corresponding authors: Stefano Cinti, E-mail: Stefano.cinti@unina.it; Arben Merkoci, E-mail: arben.merkoci@icn2.cat.
}

\begin{abstract}
The development of paper-based electroanalytical strips as powerful diagnostic tools has gained a lot of attention within the sensor community. In particular, the detection of nucleic acids in complex matrices represents a trending topic, especially when focused towards the development of emerging technologies, such as liquid biopsy. The DNA-based biosensors have been largely applied in this direction and, currently, there are two main approaches based on target/probe hybridization reported in literature, namely Signal ON and Signal OFF. In this technical note, the two approaches are evaluated in combination with paper-based electrodes, using a single strand DNA relative to H1047R (A3140G) missense mutation in exon 20 in breast cancer as the model target. A detailed comparison among the analytical performances, detection protocol, and cost associated with the two systems is provided, highlighting the advantages and drawbacks depending on the application. The present work is aimed to a wide audience, particularly for those in the field of point-of-care, and it is intended to provide the know-how to manage with the design and development stages, and to optimize the platform for the sensing of nucleic acids using a paper-based detection method.
\end{abstract}

\section{KEYWORDS: Paper-based, DNA detection, Signal ON, Signal OFF, Redox probe, Breast cancer}

The determination of nucleic acid sequences is widely reported for applications in various analytical fields, as it offers clear advantages in term of specificity. Detection of bacterial infections, food allergens, environmental pollution, and early disease diagnosis represents few of the enormous possibilities around the world of nucleic acids. ${ }^{1-3}$ Although the gold standard is represented by PCR-based approaches, the need of specialized users, dedicated equipment, and time-consuming procedures reduces the implementation of such technology outside the realms of the laboratory, i.e. in situ. ${ }^{4}$ Thus, the need for rapid and portable methods for analysis of real matrices, whilst also avoiding laboratory-bound processes, are of high demand. In particular, healthcare represents a field amenable to decrease the gap between patients and analysis; the request for point-of-care devices are growing in parallel with the rising of precision medicine. The detection of both DNA and RNA, found within bodily fluids, to diagnose diseases and infections at early-stages, and to evaluate for eventual therapeutic treatments, represents the building block for making the therapy more effective by reducing time and under/over drug dosage. Among plenty of applications, the detection of circulating nucleic acids, also known as liquid biopsy, opens up a revolutionary opportunity in cancer detection and therapy monitoring, ${ }^{5-6}$ and was recently listed within the top 10 of emerging technologies by the World Economic Forum. ${ }^{7}$ Direct access of the bloodstream offers several clear advantages, including the capture of specific nucleic acids, also avoiding the use of costly and painful tissue-biopsies. It has been successfully applied to different cancers, ${ }^{8}$ e.g. lung, pancreas, colon, breast.

Thus far, the most sensitive approach used in liquid biopsy diagnostics is BEAMing (Beads, Emulsion, Amplification, and Magnetics). ${ }^{9}$ However, sophisticated equipment and workflows limit its routine implementation. On the other hand, electroanalysis is able to provide several advantages towards the development of hand-held tests, easily interrogated with portable instrumentation, for analysis of complex samples, such as river water and blood. ${ }^{10}$ In addition, the introduction of novel paper-based platforms obtained with easy-to-develop fabrication routes, ${ }^{11}$ i.e. screen-printing and wax printing, leads to a novel concept of sustainable electroanalysis, wherein the use of paper lowers the production costs, the operative tasks, and the management of waste. ${ }^{12-13}$

Concerning the detection of nucleic acids at electrochemical surfaces, the most adopted approach is by designing a recognition probe able to specifically bind with the target of interest. The use of an electrochemical mediator is able to provide a change in electrical signal upon recognition or interaction with the target. Typically, two different experimental set-ups for sig- 
nal visualization are mainly proposed, where i) the electrochemical mediator is pre-attached at the recognition probe, or ii) it is added once the target has been recognized. Regarding the first set-up, an electrochemical platform has been produced for single and double stranded DNA detection by designing methylene $(\mathrm{MB})$ blue-tagged recognition probes and demonstrated the detection of a HIV-1 sequence. ${ }^{14}$ The presence of the target was consistent with the generation of a rigid structure which limited the electron transfer between MB and the electrode. This outcome was observed as a decrease of current, i.e. signal OFF. ${ }^{14-16}$ The other possibility recently described by Kelley et al., was the first electrochemical assay to detect circulating tumor DNA, associated with lung cancer, ${ }^{17}$ by means of a novel visualization principle. In this case, a positively charged electrochemical mediator (ruthenium hexamine chloride) was added after the target was recognized by the probe. As the probe-target adduct resulted with a higher density of negative charges, compared to the unhybridized probe, the amount of attracted ruthenium-based mediator was elevated and thus lead to an increase of electron transfer between the redox mediator and the electrode, i.e. signal ON.

In this technical note, a direct comparison between the signal ON and signal OFF approaches in paper-based platforms is provided. As a model study, the two systems are applied to detect traces of H1047R (A3140G), a missense mutation in exon 20 of the PIK3CA gene in breast cancer, which has been reported to be present in circulating blood samples of patients. ${ }^{18}$ The devices are fabricated using filter paper-based strips and utilize gold nanoparticles to anchor the recognition probes to the surface of the sensor. A comparison between the two analytical platforms, in terms of fabrication, operation and analytical performance, aims to provide readers with comprehensive insight into the capabilities and performance of the systems, whilst also placing emphasis on various relevant aspects that should be considered before and after a measurement.

\section{EXPERIMENTAL SECTION}

Reagents and Equipment. Chloroauric acid $\left(\mathrm{HAuCl}_{4}\right)$, sodium borohydride, sodium citrate, sodium chloride, potassium chloride, potassium dihydrogen phosphate $\left(\mathrm{KH}_{2} \mathrm{PO}_{4}\right)$, potassium monohydrogen phosphate $\left(\mathrm{K}_{2} \mathrm{HPO}_{4}\right)$, ruthenium hexamine chloride $\left(\mathrm{Ru}\left(\mathrm{NH}_{3}\right)_{6} \mathrm{Cl}_{3}\right)$, potassium ferricyanide $\left(\mathrm{K}_{3} \mathrm{Fe}(\mathrm{CN})_{6}\right)$, potassium ferrocyanide $\left(\mathrm{K}_{4} \mathrm{Fe}(\mathrm{CN})_{6}\right)$, 6-mercapto-1-hexanol $\left(\mathrm{HS}\left(\mathrm{CH}_{2}\right)_{6} \mathrm{OH}\right)$, and tris(2-carboxyethyl)phosphine hydrochloride (TCEP) were purchased from Sigma-Aldrich (St.Louis, MO, USA). The Methylene Blue (MB)-tagged probe as the redox reporter, was purchased from Biosearch Technologies (Novato, CA, USA) while the un-tagged probe and all the targets were purchased from IBA GmbH (Göttingen, Germany). A multi-eight portable PalmSens Instrument (PalmSens, Netherlands) was used for the electrochemical measurements.

DNA sequences. In order to compare the two approaches, screen-printed paper-based electrodes were fabricated and functionalized with two probes: 5'-HS- $\left(\mathrm{CH}_{2}\right)_{6}$ AGCCACCATGACGTGCATC $\left(\mathrm{CH}_{2}\right)_{7}-\mathrm{NH}_{2}-\mathrm{MB}-3^{\prime}$ and 5'HS- $\left(\mathrm{CH}_{2}\right)_{6}$-AGCCACCATGACGTGCATC-3' for the signal OFF and ON platform, respectively. Both the probes were modified with a thiol end at the 5'-side, to allow for the covalent attachment onto the AuNP-modified strips. A synthetic complementary 19-base single stranded DNA (5'GATGCACGTCATGGTGGCT-3') relative to H1047R (A3140G) missense mutation in exon 20 in breast cancer was used as the model target for developing both the assays. For selectivity study, the following sequences have been used: 1-MM (5'-GATGCACGTCTTGGTGGCT-3'), 3 -MM (5'GATGCACGTGTAGGTGGCT-3') and random (5'CCCCCCTTTTCTTTT-3').

Preparation of the DNA-paper based strips. Filter paperbased electrodes were fabricated as described elsewhere. ${ }^{19-20}$ Briefly, to define the working area and to isolate it from the electrical connection, wax templates were printed onto filter paper $\left(67 \mathrm{~g} / \mathrm{m}^{2}, 135 \mathrm{~mm}\right.$ caliper, Cordenons, Italy) using a wax printer (ColorQube 8580, Xerox, USA). A three-electrode system was then screen-printed by using $\mathrm{Ag} / \mathrm{AgCl}$ ink (Electrodag $477 \mathrm{SS}$, Acheson, Italy) for the reference electrode and graphite ink (Electrodag 421, Acheson, Italy) for the working and counter electrodes. Subsequently, $8 \mu \mathrm{L}$ of aqueous gold nanoparticles dispersion were drop casted onto the working electrode area. DNA probes were then immobilized onto the paper-based strips by following a reported protocol. ${ }^{21} 20 \mu \mathrm{L}$ drop of the chosen DNA probe $(50,100,200 \mathrm{nM})$ was casted on top of the working electrode area and left to incubate for $60 \mathrm{~min}$ at room temperature. The empty spaces were then passivated by drop casting a solution of $10 \mathrm{mM}$ mercapto-hexanol, left for $90 \mathrm{~min}$. The DNA modified strips were rinsed with distilled water and stored overnight at $4{ }^{\circ} \mathrm{C}$ in the working buffer solution $(50 \mathrm{mM}$ phosphate buffer containing $150 \mathrm{mM} \mathrm{NaCl}, \mathrm{pH}=7$ ). All the incubation steps were conducted in a humid chamber to avoid solvent evaporation.

Experimental setup 1: Signal ON platform. All measurements were performed using $100 \mu \mathrm{L}$ of working solution. For evaluation of the signal ON platform, DNA probes without redox label were initially immobilized onto the surface of the electrode (we optimized the probe concentration testing three different values: 50, 100 and $200 \mathrm{nM}$ ). Prior to the analysis of the sample, the electrode was rinsed with distilled water to remove any remaining storage buffer. The working solution (50 $\mathrm{mM}$ phosphate buffer containing $150 \mathrm{mM} \mathrm{NaCl}(\mathrm{pH}=7)$ ) was then added to the working area and left to incubate for a minimum of $20 \mathrm{~min}$, to allow for hybridization of the probe to the target DNA. Subsequently, $2 \mu \mathrm{L}$ of $50 \mathrm{mM}$ ruthenium hexamine chloride were added and gently mixed with a $20 \mu \mathrm{L}$ pipette tip and left for 10 mins to allow for the electrostatic attachment of $\mathrm{Ru}\left(\mathrm{NH}_{3}\right)_{6}{ }^{3+}$ around the immobilized probe and/or target/probe adduct. The paper-based strip was then gently rinsed with distilled water to remove excess of the redox mediator. It should be highlighted that, the redox mediator ( $\mathrm{Ru}$-based) is added to the working solution after the target/probe adduct is formed. The sensing principle of this particular platform exploits the electrostatic attraction between the positively charged redox mediator and the negatively charged backbone of the DNA: target/probe adduct results more negatively charged than probe, thus more Ru-based redox mediator is attracted and the signal increases. To obtain an electrochemical measurement, the electrode was rinsed with distilled water and covered with $100 \mu \mathrm{L}$ of $50 \mathrm{mM}$ phosphate buffer containing $150 \mathrm{mM} \mathrm{NaCl}(\mathrm{pH}=7)$, and the voltammetric detection was performed by DPV, scanning the potential from -0.1 to $-0.5 \mathrm{~V}$. The presence of the target 
was quantified in comparison with the signal recorded in absence of the target. The measurements were performed following the optimized protocol reported elsewhere. ${ }^{17}$

Scheme 1. Signal ON and Signal OFF platforms for paperbased electrochemical detection of nucleic acids.

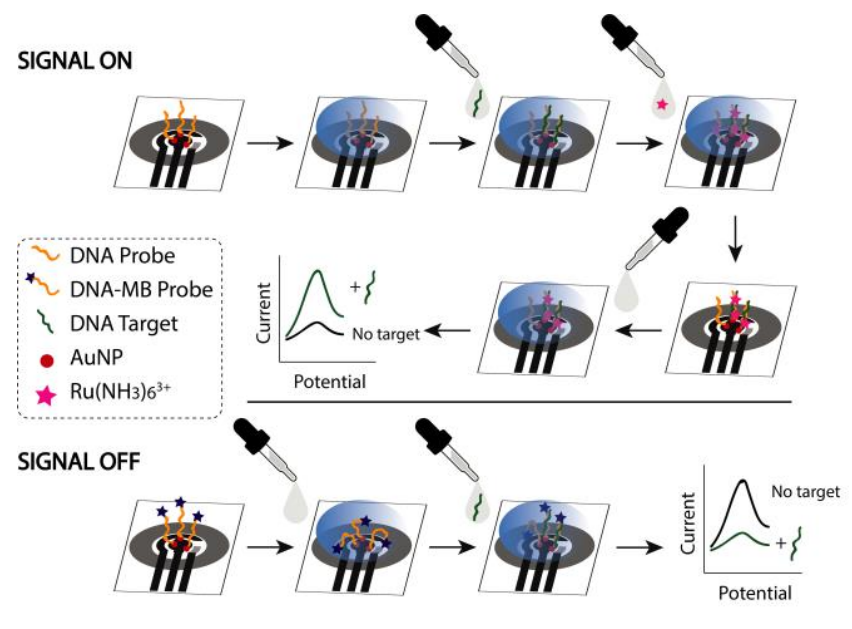

Experimental setup 2: Signal OFF platform. The signal OFF sensor fabrication was the same as the one reported for signal $\mathrm{ON}$, with the only exception that we used the MB-modified DNA probe (scheme 1). Prior to the analysis of the sample, the electrode was rinsed with distilled water to remove any remaining storage buffer, then, $100 \mu \mathrm{L}$ of buffer solution $(50 \mathrm{mM}$ phosphate buffer containing $150 \mathrm{mM} \mathrm{NaCl}(\mathrm{pH}=7)$ ) was drop casted onto the electrodes. Voltammetric measurements were then recorded until a constant peak signal was obtained (this "pretreatment" ensures that the signal decrease observed during the measurement is related to the target binding rather than the removal of weak adsorbed probes). Successively, the single stranded DNA target was added and quantified by performing voltammetric method in the range between -0.1 and $-0.5 \mathrm{~V}$ as optimized and reported elsewhere. ${ }^{14,19}$ Experimentally, when the target was present, a decrease of the recorded peak was observed due to the formation of a rigid duplex structure which reduces the interaction, i.e. electron transfer, between $\mathrm{MB}$ and electrode.

\section{RESULTS AND DISCUSSION}

DNA detection with signal ON approach. In analytical chemistry, the so-called "signal ON" approaches are those that provide an increase of detectable signal when the target analyte is present. In electroanalysis, classic are enzymatic biosensors where one of the enzymatic by-product gives the signal for quantification, for example the operation mechanism used in a glucometer. ${ }^{22}$ In the field of nucleic acids detection, in particular for liquid biopsy, a novel class of electrochemical-based genosensors for detection of nucleic acids (both DNA and RNA) has been reported. $\mathrm{Ru}\left(\mathrm{NH}_{3}\right)_{6}{ }^{3+}$ is accumulated at the working electrode through electrostatic attraction to the negatively charged DNA, and targets are detected adding ferricyanide $\left(\mathrm{Fe}(\mathrm{CN})_{6}{ }^{3-}\right){ }^{23}$ In our case, the addition of ferricyanide was omitted as it did not improve the sensitivity (Supporting Information, Figure S1): under the experimental conditions, both the high concentration of Ru-based mediator and high background signal of ferricyanide, the use of double mediators was not convenient. In addition, avoiding the use of ferricyanide means lowering both the reagents and the tasks for end-users involved in the assay. A survey of literature has revealed that the use of $200 \mathrm{nM}$ of DNA probes corresponds to a density of ca. $10^{12}$ molecules $/ \mathrm{cm}^{2}$ onto the electrode. ${ }^{24}$
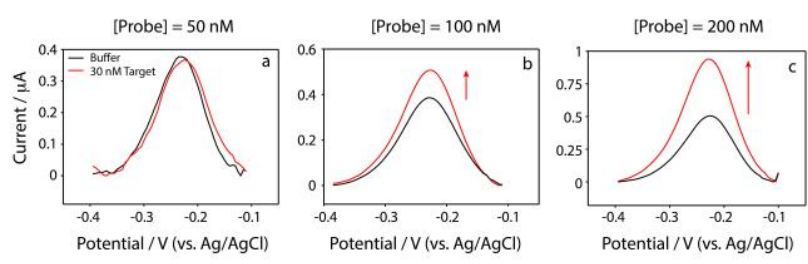

Figure 1. Evaluation of the DNA probe effect for the Signal ON system, using a) 50, b) 100 , and c) $200 \mathrm{nM}$ of recognizing probe in absence (black line) and in presence (red line) of $30 \mathrm{nM}$ target. Working solution is $50 \mathrm{mM}$ phosphate buffer containing $150 \mathrm{mM} \mathrm{NaCl}(\mathrm{pH}=7)$.

Current increase of $25 \%$ and $80 \%$ were observed for $100 \mathrm{nM}$ and $200 \mathrm{nM}$ densities, respectively, while the current remained unchanged for the $50 \mathrm{nM}$ probe density. The higher signal change observed for the sensor with more probes on the surface depends on two important factors: A) the higher probability of binding target molecules for a higher probe density and $\mathrm{B}$ ) the accumulation of more $\mathrm{Ru}\left(\mathrm{NH}_{3}\right)_{6}{ }^{3+}$ on the electrode surface due to the presence of more probe/target adducts. Regarding the lack of signal change for the sensor fabricated using $50 \mathrm{nM}$ probe, it depends on the fact that we are in the high ligand-depletion regime (probe concentration approximately of $5 \mathrm{nM}$ vs a Kd of $25 \mathrm{nM}){ }^{25}$ Another important aspect to keep in mind when using low deposition concentration in a signal ON format on a paper-based device is that it requires harsher washing step than those generally used on plastic/ceramic SPE or glassy carbon electrode. This harsher washing can indeed affect the number of capture probes present on the working electrode, showing a lower signal that expected (probes/AuNPs can be washed away during the washing step thus the available negative charges are lower thus the measurement will produce a lower signal), Figure S2 in Supporting Information File. Given the higher signal change, the 200-nM DNA probe modified strip has been adopted to detect breast cancer target in the concentration range between 0.1 and $3000 \mathrm{nM}$ (Figure 2). Moreover, the use of single-use platforms allows for evaluating the repeatability of the platform. 


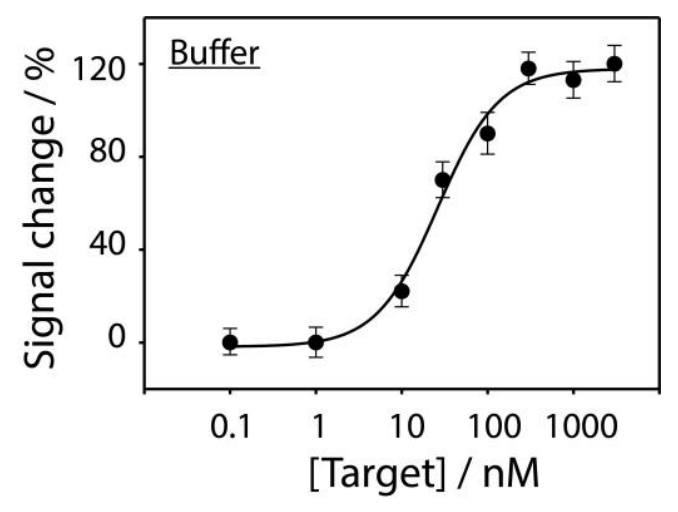

Figure 2. Binding curve (fitted to the hyperbolic Langmuir isotherm - $\mathrm{R}^{2}$ value of 0.990 ) obtained with the Signal ON approach by using screen-printed electrodes onto filter paper challenged with target concentration ranging between $0.1-3000 \mathrm{nM}$ target. Working solution is $50 \mathrm{mM}$ phosphate buffer containing $150 \mathrm{mM} \mathrm{NaCl}(\mathrm{pH}=7)$.

The detection of mutations related to breast cancer in standard solution has been consistent with a detection limit of $5 \mathrm{nM}$ (computed using the 3 sigma method), a calculated affinity of $26 \pm 5 \mathrm{nM}$ (calculated fitting the data to the hyperbolic Langmuir isotherm), and a linear range between 10 and $100 \mathrm{nM}$ (calculated as the transition from $10 \%$ to $90 \%$ site occupancy). ${ }^{26}$ The repeatability of the system was described by a relative standard deviation of $15 \%(n=8)$ calculated on the binding curve. The eight calibration points of each binding curve are the result of three experiments that have been performed with single-use strips: in total, twenty-four strips have been used for each binding curve, evidencing a satisfactory reliability associated with the entire manufacturing process. After evaluation of the performance of the signal ON platform in standard solution, a real matrix scenario was simulated using whole and 50\%, 25\% and $12.5 \%$-diluted blood as model. Due to the complex composition of blood, containing proteins, lipids, salts, etc., the fouling of the modified electrode, due to stacking and interactions of the components and the surface, becomes problematic (it sterically prevents the accumulation of $\mathrm{Ru}\left(\mathrm{NH}_{3}\right)_{6}{ }^{3+}$ on the electrode surface and negatively charged contaminants can actively sequestrate it) and the washing step proved to be inadequate for the complete removal of the matrix from the working electrode. We obtained no electrochemical signal. While this problem could be solved using plastic or ceramic SPE, which can be mildly washed and the complete removal of contaminant achieved, in paper-based platform is more problematic. The net of cellulose fibers entraps cells and proteins making the removal of fouling agents extremely difficult, whilst a vigorous washing step can cause damages to the hybrid nanocomposite, i.e. AuNPs/DNA, onto the working electrode surface.

DNA detection with signal OFF approach. The second platform tested was made with the same recognition probe as aforementioned; however, in this case, MB was covalently attached at the free end of the probe. Although it could appear as a small difference, this characteristic makes this platform reagentless (the redox mediator is already included within the paper-based strip) and utilizes a different sensing mechanism (the formation of a rigid probe/target duplex reduces the electron transfer at the electrode). As for the previous study, the same solution of probe densities has been taken into account for strip modification, i.e. 50, 100 and $200 \mathrm{nM}$, and the results are displayed in figure 3.
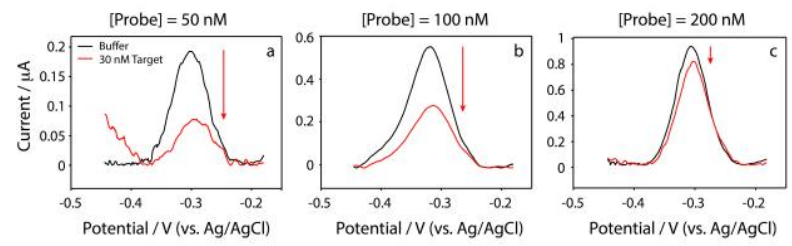

Figure 3. Evaluation of the DNA probe density on the Signal ON system, using a) 50, b)100, and c) $200 \mathrm{nM}$ of recognizing probe in absence (black line) and in presence (red line) of 30 $\mathrm{nM}$ target. Working solution is $50 \mathrm{mM}$ phosphate buffer containing $150 \mathrm{mM} \mathrm{NaCl}(\mathrm{pH}=7)$.

Unlike the behavior observed for the signal ON platform, here, the maximum signal change, $-40 \%$, was obtained for the sensors prepared using the $50 \mathrm{nM}$ probe solution. While $100 \mathrm{nM}$ and $200 \mathrm{nM}$ produced respectively ca. $-25 \%$ and $-6 \%$. The complete opposite behavior compared to signal $\mathrm{ON}$ sensors depends on the sensor architecture itself. In fact in signal OFF sensors we start from the maximum signal already and we want to see a signal decrease for the minimum amount of target possible. Thus having a higher packing density means that we need more target molecules to observe a signal decrease (the more probes on the surface, the more probes need to change conformation before seeing a signal change). Although the largest variation current was obtained with the lowest probe density, $50 \mathrm{nM}$, the signal acquired contained a high level of noise. Thus, further measurements were conducted using densities of $100 \mathrm{nM}$ as the best compromise for current variation and signal quality. Similar to the signal ON platform, the analytical performance of the signal OFF platform was evaluated in buffer solution with varying concentrations of the target (Figure 4)

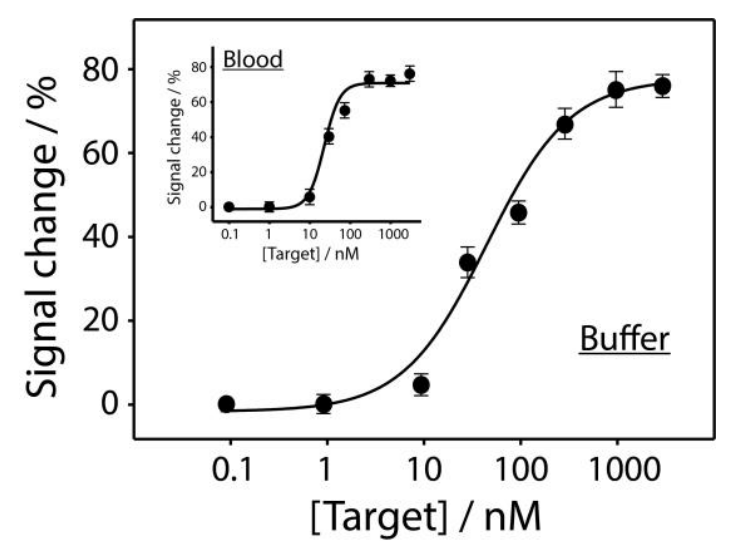

Figure 4. Binding curve (fitted to the hyperbolic Langmuir isotherm - $\mathrm{R}^{2}$ value of 0.993 ) obtained with the Signal OFF approach by using screen-printed electrodes onto filter paper challenged with target concentration ranging between 0.1-3000 nM target. Working solution is $50 \mathrm{mM}$ phosphate buffer containing $150 \mathrm{mM} \mathrm{NaCl}(\mathrm{pH}=7)$. Inset: $0.1-3000 \mathrm{nM}$ target detected in $12.5-\%$ diluted blood.

In this case, as shown in Figure 4, the limit of detection was calculated to be $6 \mathrm{nM}$ (using the 3 sigma method), the binding 
constant was $40 \pm 6 \mathrm{nM}$ (for the fitting to the hyperbolic Langmuir isotherm), and the linear range was between 20 and 300 $\mathrm{nM}$ (calculated as the transition from $10 \%$ to $90 \%$ site occupancy). The repeatability of the system was described by a relative standard deviation of $12 \%(n=8)$. One of the main differences of the signal OFF platform, in comparison to the signal $\mathrm{ON}$, is the non-incorporation of the redox mediator onto the working surface during the fabrication steps. This detail is advantageous to this type of detection as it negates the requirement of post washing steps for the removal of excess mediators, as seen with signal ON platforms, and allows for testing with complex matrices. As aforementioned, complex matrices, such as blood, present their own challenges, namely fouling of the electrode surface in this case. As such, a comparison of various dilutions of whole blood, $50 \%, 25 \%$ and $12.5 \%$, and its effects on the signal OFF platform was conducted. The optimal dilution was revealed to be $12.5 \%$ and, upon interaction with the synthetic H1047R (A3140G) DNA strands between 0.1-3000 nM, the binding constant was observed to be $23 \pm 4 \mathrm{nM}$, which was of the same order of magnitude of the measurements obtained in standard solution. In addition, the calculated detection limit was also similar within the experimental errors. It should be noted that the possibility of working in the cathodic range of applied potentials, (MB exchanges electrons from -0.5 to -0.1 $\mathrm{V})$ reduces the possible interference by easily oxidizing compounds which are physiologically occurring, ${ }^{27}$ e.g. ascorbic acid, uric acid, and acetaminophen.

Signal ON vs. Signal OFF. Within the field of (bio)sensors, and more specifically in the field of nucleic acid detection, this technical note is a demonstration of an experimental tutorial towards optimal selection of an electroanalytical platform. Of course, factors such as facilities, specialization of personnel and specific analytical needs, will influence the selection of the most suitable platform. A comparative overview of the differences between these techniques are summarized in table 1 .

Table 1. Comparison between Signal ON and Signal OFF onto paper-based strips for nucleic acid detection.

\begin{tabular}{|l|l|l|}
\hline & Signal ON & Signal OFF \\
\hline Principle & $\begin{array}{l}\mathrm{Ru}\left(\mathrm{NH}_{3}\right)_{6}{ }^{3+} \text { electro- } \\
\text { statically attracted to } \\
\text { DNA. More is the } \\
\text { [Target], signal in- } \\
\text { creases. }\end{array}$ & $\begin{array}{l}\text { Probe is MB- } \\
\text { tagged. The pres- } \\
\text { ence of [Target] } \\
\text { reduces the MB } \\
\text { contact with the } \\
\text { electrode, and the } \\
\text { signal decreases. }\end{array}$ \\
\hline Procedure & $\begin{array}{l}\text { 1.Probe/Target bind- } \\
\text { ing, 2. Addition redox } \\
\text { probe, 3. Washing, 4. } \\
\text { Measurement. }\end{array}$ & $\begin{array}{l}\text { 1.Probe/Target } \\
\text { binding, 2. Meas- } \\
\text { urement. }\end{array}$ \\
\hline Performance & Low nM & Low nM \\
\hline Real matrices & Requires washing & $\begin{array}{l}\text { No } \\
\text { needed washing }\end{array}$ \\
\hline Cost & Cheap & Expensive \\
\hline
\end{tabular}

Although the performance of the two detection systems, developed onto paper-based electrochemical strips, display similar detection limits in the range of low nanomolar, there are still various considerations that need to be addressed. The signal ON strategy requires extra steps, namely additional washing steps where specific attention is required, as there is a high risk of removal of the pre-embedded recognition elements, thus affecting the repeatability of the measurements. We must say though that additional washing steps may result useful to discriminate between target with one or more mismatches, whose weaker bindings to the probe could be more easily detected. Moreover, the post washing step also limits the platform for analysis of whole blood. In fact, because of the time required for sufficient hybridization between probe and target, build up or fouling from the other components of the blood matrix, such as blood cells and proteins, can occur and the post washing step becomes ineffective, resulting in false positive measurements. However, once again, it should be noted that the use of other substrates, i.e. glass, plastic or ceramic, could minimize this issue during the washing steps. Another possible solution is the implementation of blood filters on top of the working electrode, minimizing the presence of cells on the electrode surface. On the other hand, the measurement with the Signal OFF platform proves to be easier in terms of operation steps; however, it should be considered that the cost of a tagged probe is 4-5 fold higher than that of the un-tagged probes used in the former system. In addition, from an analytical point of view, the signal OFF could suffer from the presence of background signals which may limit its application for trace detection. Instead, regarding the signal ON platform, the alternative use of neutral probes, e.g. PNA, as reported in literature, ${ }^{28}$ can represent an advantage this method, by lowering the background current (because the positively charged redox probe is not electrostatically attracted in presence of a neutral probe), but it would make the system even more expensive, so it should be carefully weighted. Moreover, the selectivity of both approaches has been tested in presence of 1 mismatch, 3 mismatches and fully-random probes (Supporting Information, Figure S3 and Figure S4): as reported, no relevant differences have been highlighted.

\section{CONCLUSIONS}

The rising demand for user-friendly analytical devices highlights the versatility and potential of paper-based tools as a pivotal forerunner for the development of (bio)sensors. Emerging technologies, such as liquid biopsy, can be coupled with electroanalytical platforms and corresponding technologies with easy fabrication routes. In this technical note, the two most common strategies for detection of nucleic acids are compared in a paper-based platform. Signal ON and Signal OFF systems have been implemented towards the determination of a single strand DNA relative to a missense mutation in breast cancer. Although the two methods, within the experimental setup, have showed similar analytical performance, e.g. detection limit in the low $\mathrm{nM}$ level and calculated binding constant in the $\mathrm{nM}$ range, some differences have been observed. For each platform, some key factors are to be considered prior to the fabrication and use of the paper-based strip. For the signal OFF platform, as the redox mediator is already integrated into the platform, this negates the requirements of any additional reagents. However, the cost of the signal OFF platform is typically 4-5 fold higher than the signal ON platform, due to the modification of the probe with a tag. From the other side, the main limitations of utilizing the "cheaper" signal ON system is the necessity of external chemicals, the need of extra washing steps and the possibility of electrode fouling from complex matrices. Both approaches are promising in terms of costs and miniaturization; 
however, for in-situ application performed by non-specialized users, the Signal OFF represents the optimal compromise of manufacturing and ease of use.

\section{AUTHOR INFORMATION}

\section{Corresponding Author}

*E-mail: stefano.cinti@unina.it

*E-mail: arben.merkoci@icn2.cat

\section{ACKNOWLEDGMENT}

S.C. acknowledges Marie Skłodowska-Curie Actions Individual Fellowship, this project has received funding from the European Union's Horizon 2020 research and innovation programme under the Marie Skłodowska-Curie grant agreement No 794007. C.P. acknowledges Marie Skłodowska-Curie Actions Individual Fellowship, this project has received funding from the European Union's Horizon 2020 research and innovation programme under the Marie Skłodowska-Curie grant agreement No 795635. The ICN2 is funded by the CERCA Programme / Generalitat de Catalunya. The ICN2 is supported by the Severo Ochoa program of the Spanish Ministry of Economy, Industry and Competitiveness (MINECO, grant No. SEV-2017-0706). Financial support was obtained under MAT2017-87202-P.

\section{REFERENCES}

1) Ranallo, S.; Porchetta, A.; Ricci, F. Anal. Chem. 2018, 91, 4459.

2) Miao, Y.; Sun, X.; Lv, J.; Yan, G. Anal. Chem. 2019, 91, 50365042 .

3) Böhme, K.; Calo-Mata, P.; Barros-Velázquez, J.; Ortea, I. J. Agric. Food Chem. 2019, 67, 3854-3864.

4) Yu, A. C.; Vatcher, G.; Yue, X.; Dong, Y.; Li, M. H.; Tam, . H.; Tsang, P. Y.; Wong, A. K.; Hui, M. H.; Yang, B.; et al. Front. Med. 2012, 6, 173-186

5) Newman, A. M.; Bratman, S. V.; To, J.; Wynne, J. F.; Eclov, N. C.; Modlin, L. A.; Liu, C. L.; Neal, J. W.; Wakelee, H. A.; Merritt, R. E.; Shrager, J. B.; Loo Jr, B. W.; Alizadeh, A. A.; Diehn, M. Nat. Med. 2014, 20, 548-554.

6) Siravegna, G., Marsoni, S., Siena, S., \& Bardelli, A. (2017). Nat. Rev. Clin. Oncol. 2017, 14, 531-548.

7) https://www.weforum.org/agenda/2017/06/these-are-the-top10-emerging-technologies-of-2017/;12C

8) Alix-Panabieres, C.; Pantel, K. Clin. Chem. 2013, 59, 110-118.

9) Diehl, F.; Li, M.; Dressman, D.; He, Y.; Shen, D.; Szabo, S.; Diaz Jr, L. A.; Goodman, S. N.; David, K. A.; Juhl, H.; Kinzler, K. W.; Vogelstein, B. Proc. Natl. Acad. Sci. 2005, 102, 1636816373.

10) Labib, M.; Sargent, E. H.; Kelley, S. O. Chem. Rev. 2016, $116,9001-9090$
11) López-Marzo, A. M.; Merkoçi, A. Lab Chip 2016, 16, 31503176.

12) Arduini, F.; Cinti, S.; Scognamiglio, V.; Moscone, D. Compr. Anal. Chem. 2017, 77, 385.

13) Yang, Y.; Noviana, E.; Nguyen, M. P.; Geiss, B. J.; Dandy, D. S.; Henry, C. S. Paper-based microfluidic devices: emerging themes and applications. Anal. Chem. 2016, 89, 71-91.

14) Patterson, A.; Caprio, F.; Vallée-Bélisle, A.; Moscone, D.; Plaxco, K. W.; Palleschi, G.; Ricci, F. Anal. Chem. 2010, 82, 9109-9115.

15) Ricci, F.; Plaxco, K. W. Microchim. Acta 2008, 163, 149-155.

16) Li, H.; Somerson, J.; Xia, F.; Plaxco, K. W. Anal. Chem. 2018, 90, 10641-10645.

17) Das, J.; Ivanov, I.; Sargent, E. H.; Kelley, S. O. J. Am. Chem. Soc. 2016, 138, 11009-11016.

18) Levine, D. A.; Bogomolniy, F.; Yee, C. J.; Lash, A.; Barakat, R. R.; Borgen, P. I.; Boyd, J. Clin. Cancer Res. 2005, 11, 28752878 .

19) Cinti, S.; Proietti, E.; Casotto, F.; Moscone, D.; Arduini, F. Anal. Chem. 2018, 90, 13680-13686.

20) Cinti, S.; Moscone, D.; Arduini, A. Nat. Protoc. 2019, DOI: 10.1038/s41596-019-0186-y.

21) Xiao, Y.; Lai, R. Y.; Plaxco, K. W. Nat. Protoc. 2007, 2, 2875-2880.

22) Turner, A.P.F. Chem. Soc. Rev. 2013, 8, 3175-3648.

23) Lapierre, M. A.; O’Keefe, M. M.; Taft, B. J.; Kelley, S. O. Anal. Chem. 2003, 75, 6327-6333.

24) Ricci, F.; Lai, R. Y.; Heeger, A. J.; Plaxco, K. W.; Sumner, J. J. Langmuir 2007, 23, 6827-6834.

25) Esteban Fernańdez de Ávila,B.; Watkins, H. M.; Pingarroń, J. M.; Plaxco, K. W.; Palleschi, G.; Ricci, F. Anal. Chem. 2013, 85, 6593-6597.

26) Vallée-Bélisle, A.; Ricci, F.;Plaxco, K. W. J. Am. Chem. Soc. 2012, 134, 2876-2879.

27) Cinti, S.; Cusenza, R.; Moscone, D.; Arduini, F. Talanta 2018, 187, 59-64.

28) Fang, Z.; Kelley, S. O. Anal. Chem. 2008, 81, 612-617. 


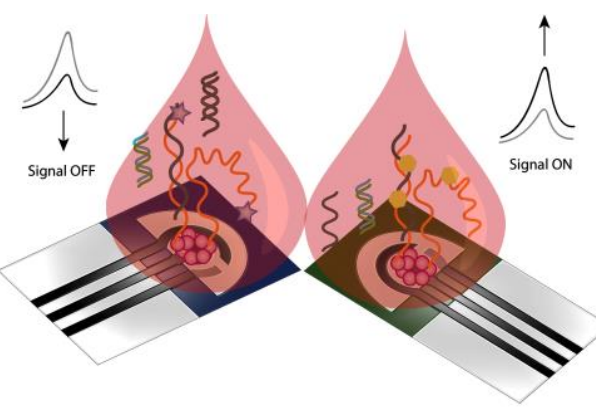

